\title{
Chattering and Differential Signal Processing in Identified Motion- Sensitive Neurons of Parallel Visual Pathways in the Chick Tectum
}

\author{
Harald Luksch, ${ }^{1}$ Harvey J. Karten, ${ }^{2}$ David Kleinfeld, ${ }^{3}$ and Ralf Wessel ${ }^{4}$ \\ 1/nstitute of Biology II, Rheinisch-Westfälische Technische Hochschule Aachen, 52074 Aachen, Germany, Departments of \\ ${ }^{2}$ Neuroscience and ${ }^{3}$ Physics, University of California at San Diego, La Jolla, California 92093, and ${ }^{4}$ Department of \\ Physics, Washington University, St. Louis, Missouri 63130
}

\begin{abstract}
At least three identified cell types in the stratum griseum centrale (SGC) of the chick optic tectum mediate separate pathways from the retina to different subdivisions of the thalamic nucleus rotundus. Two of these, SGC type I and type II, constitute the major direct inputs to rotundal subdivisions that process various aspects of visual information, e.g., motion and luminance changes. Here, we examined the responses of these cell types to somatic current injection and synaptic input. We used a brain slice preparation of the chick tectum and applied whole-cell patch recordings, restricted electrical stimulation of dendritic endings, and subsequent labeling with biocytin. Type I neurons responded with regular sequences of bursts ("chattering") to depolarizing current injection. Electrical stimulation of retinal afferents evoked a sharp-onset EPSP/burst response that was blocked with CNQX. The sharp-onset EPSP/burst
\end{abstract}

response to synaptic stimulation persisted when the soma was hyperpolarized, thus suggesting the presence of dendritic spike generation. In contrast, the type II neurons responded to depolarizing current injection solely with an irregular sequence of individual spikes. Electrical stimulation of retinal afferents led to slow and long-lasting EPSPs that gave rise to one or several action potentials. In conclusion, the morphological distinct SGC type I and II neurons also have different response properties to retinal inputs. This difference is likely to have functional significance for the differential processing of visual information in the separate pathways from the retina to different subdivisions of the thalamic nucleus rotundus.

Key words: visual system; cellular physiology; optic tectum; whole-cell patch recording; synaptic stimulation; dendrites; motion
The avian optic tectum plays a key role in visual information processing. It receives the bulk of retinal afferents (Bravo and Pettigrew, 1981; Remy and Güntürkün, 1991), and lesions of the tectof ugal pathway have strong effects on the animal's response to visual cues (Hodos and Karten, 1974; Chaves and Hodos, 1998; Laverghetta and Shimizu, 1999). Of practical importance is the anatomical separation of retinal afferents and tectal projection neuron dendrites that makes the avian tectum a powerful in vitro model for studying the fundamental problem of how the brain processes visual information.

The avian tectum consists of well separated laminas that contain specific retinal afferents, interneurons, or projection neurons (Ramón y Cajal, 1911; Angaut and Reperant, 1976; Hunt and Künzle, 1976; Hardy et al., 1985; Luksch et al., 1998). Retinal afferents terminate in retinotopic organization in layers 2-7 with the exception of layer 6 (Hunt and Webster, 1975). In turn, the strongest tectal projection stems from deep tectal layer 13 [stratum griseum centrale (SGC)] and innervates the thalamic nucleus rotundus bilaterally (Karten and Revzin, 1966; Hunt and Künzle, 1976). These neurons in deep tectal layers possess large receptive fields of up to $180^{\circ}$ (Jassik-Gerschenfeld and Guichard, 1972;

Received Feb. 28, 2001; revised May 31, 2001; accepted May 31, 2001.

This work was supported by German Research Foundation Grant Lu-622 2-1 (H.L.) and by National Science Foundation Grant IBN-9604799 (R.W.). We thank Dan Major for valuable discussions, Jörg Lippert for critical reading of this manuscript, and Agnieszka Brzozowska-Prechtl and Marianne Dohms for technical assistance.

Correspondence should be addressed to Dr. H. Luksch, Institut für Biologie II, Rheinisch-Westfälische Technische Hochschule Aachen, Kopernikusstr. 16, D-52074 Aachen, Germany. E-mail: luksch@bio2.rwth-aachen.de.

Copyright (C) 2001 Society for Neuroscience $0270-6474 / 01 / 216440-07 \$ 15.00 / 0$
Hughes and Pearlman, 1974; Frost and DiFranco, 1976) and show a marked preference for moving stimuli (Jassik-Gerschenfeld et al., 1970; Jassik-Gerschenfeld and Guichard, 1972; Frost, 1978; Frost and Nakayama, 1983; Troje and Frost, 1998).

The tectorotundal projection has a complex topography in which specific SGC subtypes innervate restricted rotundal subdivisions (Benowitz and Karten, 1976; Karten et al., 1997; Luksch et al., 1998; Hellmann and Güntürkün, 2001). Specifically, SGC type I (SGC-I) neurons, with dendritic endings in the retinorecipient layer $5 \mathrm{~b}$, project to the anterior and centralis rotundal divisions, whereas the SCG type II (SGC-II) neurons, with dendritic endings below the retinorecipient tectal layers, project to the posterior and triangularis rotundal divisions (Benowitz and Karten, 1976; Luksch et al., 1998). Of functional importance, rotundal subdivisions preferentially respond to different aspects of visual information, e.g., color, luminance, motion, and looming (Revzin, 1981; Wang and Frost, 1992; Wang et al., 1993).

Because the SGC-I and -II neurons present the major direct inputs to the rotundal subdivisions, a description of their physiology is essential to understand the visual information processing in the two separate retinotectorotundal pathways. In this study, we investigated the physiological properties of SGC-I and -II neurons. We took advantage of the strict separation between retinal afferents and SGC dendrites and studied cellular responses to somatic current injection and retinal inputs in a brain slice preparation.

\section{MATERIALS AND METHODS}

Thirty-five White Leghorn chick hatchlings (Gallus gallus) of $<5 \mathrm{~d}$ of age were used in this study. All procedures used in this study were approved by the local authorities and conform to the guidelines of the National 


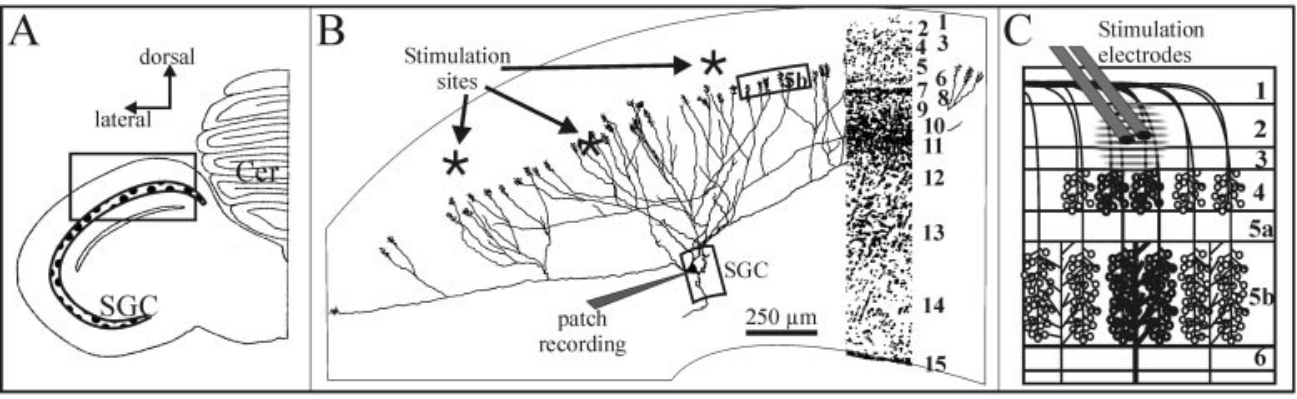

Figure 1. Schematic of the slice preparation. $A$, Overview of the transversal midbrain slice. Inset, The tectal area shown in $B . B$, Reconstruction of an SGC-I neuron superimposed on the tectal outline. Inset (right), The layers visible in a Nissl stain or with acridinorange incubation in vitro. Note the positioning of the stimulation electrodes above and within the retinorecipient layer $5 \mathrm{~b}$ (boxed area). $C$, Schematic of the spatial separation of the electrostimulation and the postsynaptic ele-

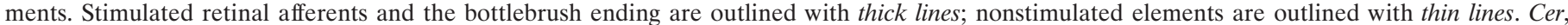
Cerebellum.

Institutes of Health Guide for the Care and Use of Laboratory Animals. Tectal slices were prepared as described previously (Dye and Karten, 1996). Animals were anesthetized with a mixture of ketamine and xylazine (40 and $12 \mathrm{mg} / \mathrm{kg}$, respectively, i.m.) and decapitated, and the brain was quickly removed and immersed in ice-cold, oxygenated, and sucrose-substituted artificial CSF $(240 \mathrm{~mm}$ sucrose, $3 \mathrm{~mm} \mathrm{KCl}, 3 \mathrm{~mm}$ $\mathrm{MgCl}_{2}, 1.2 \mathrm{~mm} \mathrm{NaH}_{2} \mathrm{PO}_{4}, 23 \mathrm{~mm} \mathrm{NaHCO}$, and $11 \mathrm{~mm}$ D-glucose). The forebrain, cerebellum, and medulla oblongata were discarded, and the remaining tectodiencephalic area was separated by a midsagittal cut. The optic tectum was sectioned at $500 \mu \mathrm{m}$ on a vibratome (Cambden Vibroslice; World Precision Instruments, Sarasota, FL) in the transverse plane. Slices were collected in oxygenated artificial CSF (ACSF; $120 \mathrm{~mm}$ $\mathrm{NaCl}, 3 \mathrm{~mm} \mathrm{KCl}, 1 \mathrm{~mm} \mathrm{MgCl} 2,2 \mathrm{~mm} \mathrm{CaCl}_{2}, 1.2 \mathrm{~mm} \mathrm{NaH}_{2} \mathrm{PO}_{4}, 23 \mathrm{~mm}$ $\mathrm{NaHCO}_{3}$, and $11 \mathrm{~mm}$ D-glucose) and kept submerged in a chamber that was continuously bubbled with carbogen $\left(95 \%\right.$ oxygen and $\left.5 \% \mathrm{CO}_{2}\right)$ at room temperature. In initial experiments, the entire slice was labeled by adding $0.01 \%$ acridin-orange (Molecular Probes, Eugene, OR) to the ACSF. Slices were allowed to recover for $\geq 1 \mathrm{hr}$ before recording.

The slice was transferred to a custom-built submersion-type chamber mounted on either a mobile-stage or fixed-stage microscope (Zeiss, Oberkochen, Germany) equipped with long-range working optics. The slice was gently held to the bottom mesh of the chamber with a Teflon ring, and the chamber was continuously perfused with oxygenated ACSF at room temperature. In previous experiments, the layers of the optic tectum were visualized by epifluorescent illumination of the acridinorange-treated slices. However, because several tectal layers (e.g., layers 6,8 , and 13) are readily visible with bright-field illumination, we omitted the acridin-orange incubation in the subsequent experiments.

Electrostimulation was achieved by insertion of bipolar tungsten electrodes under visual control either into the upper retinorecipient layers (2-4) or into layer $5 \mathrm{~b}$ with a three-axis hydraulic drive (Narishige, Tokyo, Japan). Electrodes were custom-built from $25 \mu \mathrm{m}$, insulated tungsten wires (California Fine Wire) that were glued together with cyanoacrylate and mounted in glass microcapillaries for stabilization. The wires protruded several hundred micrometers from the capillaries, and the tips were cut at an angle to increase the exposed area. Current pulses $(20-400 \mu \mathrm{A} ; 500-2000 \mu \mathrm{sec})$ were generated by stimulus isolators (A360, World Precision Instruments; or SIU90, Neuro Data Instruments). Because of the very restricted stimulation with bipolar wires of $25 \mu \mathrm{m}$ diameter, electrical stimulation was not successful in all preparations. In some of these cases, however, repositioning the stimulation electrodes resulted in successful stimulation. Electrode positions could easily be retrieved in the histological sections by the insertion tracks (Fig. 1).

Whole-cell patch recordings were obtained with glass micropipettes pulled from borosilicate glass $(1.5 \mathrm{~mm}$ outer diameter; $0.86 \mathrm{~mm}$ inner diameter; AM Systems, Carlsborg, WA) on a horizontal puller (Sutter Instruments, San Rafael, CA, or DMZ Universal Puller, Zeitz, Germany) and filled with a solution containing $100 \mathrm{~mm} \mathrm{~K}$-gluconate, $40 \mathrm{~mm}$ $\mathrm{KCl}, 10 \mathrm{~mm}$ HEPES, $0.1 \mathrm{mM} \mathrm{CaCl}_{2}, 2 \mathrm{~mm} \mathrm{MgCl} 2,1.1 \mathrm{~mm}$ EGTA, and 2 mM Mg-ATP; $\mathrm{pH}$ was adjusted to 7.2 with $\mathrm{KOH}$. Additionally, the solution contained $0.5 \%(\mathrm{w} / \mathrm{v})$ biocytin to label the recorded neurons. Electrodes were advanced through the tissue with a hydraulic micromanipulator (Narishige) while constant positive pressure was applied, and the electrode resistance was monitored by short current pulses. After the electrode had attached to a membrane and formed a seal, access to the cytosol was achieved by brief suction. Whole-cell patch recordings (current clamp) were performed with the amplifier (Axoclamp 2B, Axon Instruments, Foster City, CA; or SEC 5 0L, npI-electronic, Tamm) in the bridge mode. The series resistance was estimated by toggling between the bridge and the discontinuous current clamp (DCC) mode. The series resistance was compensated with the bridge balance. For DCC mode, the sample rate was set to $5 \mathrm{kHz}$, and the capacitance compensation was optimized by monitoring the output on an oscilloscope. Analog data were low-pass filtered (four-pole Butterworth) at $1 \mathrm{kHz}$, digitized at $5 \mathrm{kHz}$, stored, and analyzed on a personal computer equipped with a data application card (AT-M10-16E-1) and LabView software (both National Instruments, Austin, TX). To verify synaptic transmission, non-NMDA glutamate receptors were blocked with CNQX that was bath-applied by switching the continuous ACSF supply to ACSF containing 10-50 $\mu \mathrm{M}$ CNQX. All data are presented as the mean \pm SD.

After recording and labeling a maximum of two cells in one slice, we kept the slices in oxygenated ACSF for an additional $30 \mathrm{~min}$ and subsequently fixed the slices by immersion in $4 \%$ paraformaldehyde in phosphate buffer (PB, 0.1 M, pH 7.4) for at least $4 \mathrm{hr}$. Slices were then washed in PB for at least $4 \mathrm{hr}$, immersed in $30 \%$ sucrose in PB for at least $2 \mathrm{hr}$, and resectioned at $60 \mu \mathrm{m}$ on a freezing microtome. The sections were collected in $\mathrm{PB}$, and the endogenous peroxidase was blocked by a 15 min immersion in $0.6 \%$ hydrogen peroxide in methanol. The tissue was washed several times in $\mathrm{PB}$ and then incubated in the avidin-biotin complex solution (ABC Elite kit; Vector Laboratories, Burlingame, CA), and the reaction product was visualized with a heavy metal-intensified $\mathrm{DAB}$ protocol. After several washes in $\mathrm{PB}$, the sections were mounted on gelatin-coated slides, dried, dehydrated, and coverslipped. Sections were inspected for labeled neurons with differential interference contrast optics, and only data from cells that could unequivocally be classified according to the criteria given by Luksch et al. (1998) were taken for further analysis. Several of the labeled neurons were reconstructed at medium magnification $(20-40 \times)$ with a camera lucida on a Leica microscope. Digital images of selected neurons were captured with an Axiocam mounted on a photomicroscope (Axiophot) and collected into Axiovision software (all Zeiss).

\section{RESULTS}

We obtained stable whole-cell patch recordings from a total of 96 neurons in the chick SGC. Because of the large extension of the dendritic field of SGC neurons, dendrites of cells at the surface of the slice tend to be truncated. We therefore aimed to record from neurons that were positioned in the middle of the slice. The series resistances of the recordings varied between 10 and $40 \mathrm{M} \Omega$ and were routinely compensated. Of the neurons that were successfully recorded and labeled with biocytin afterward, 55\% were filled sufficiently to allow unequivocal classification into one of the two major SGC cell types. The SGC-I neurons have dendritic endings in the retinorecipient layer $5 \mathrm{~b}$ and axons projecting to anterior and centralis rotundal divisions. The SGC-II neurons have dendritic endings below the retinorecipient tectal layers and axons projecting to posterior and triangularis rotundal divisions (Benowitz and Karten, 1976; Luksch et al., 1998). Three of the filled cells belonged to additional SGC cell classes and were thus omitted from our analysis, leaving 35 SGC-I neurons and 15 SGC-II neurons. A photomicrograph of a labeled SGC-I neuron is depicted in Figure 2 to show the quality of the label. 


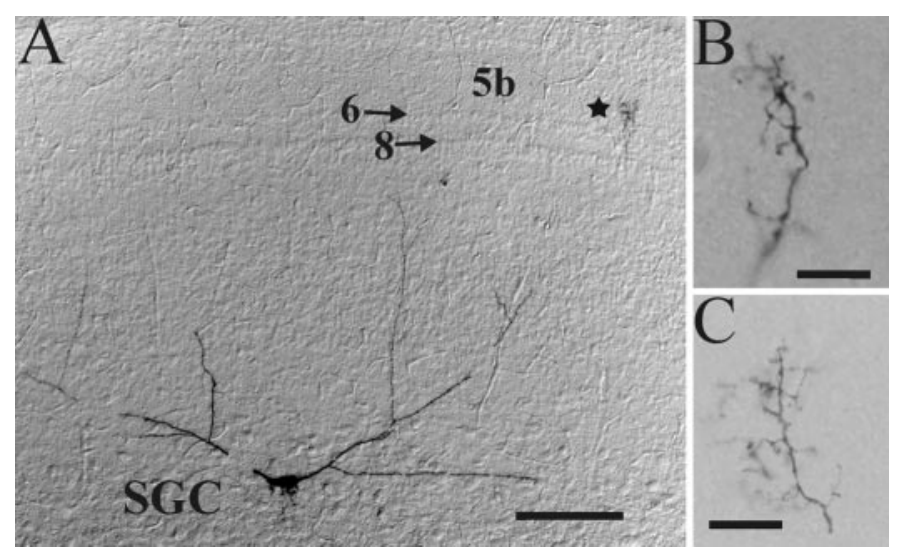

Figure 2. A, Digital image of soma, basal dendrites, and one bottlebrush ending (asterisk) of a biocytin-labeled SGC-I neuron viewed with differential interference contrast optics to show the tectal layering (layers $5 \mathrm{~b}, 6$, 8 indicated). $B, C$, Examples of bottlebrush endings of the same cell at higher magnification. Scale bars: $A, 100 \mu \mathrm{m} ; B, C, 10 \mu \mathrm{m}$.

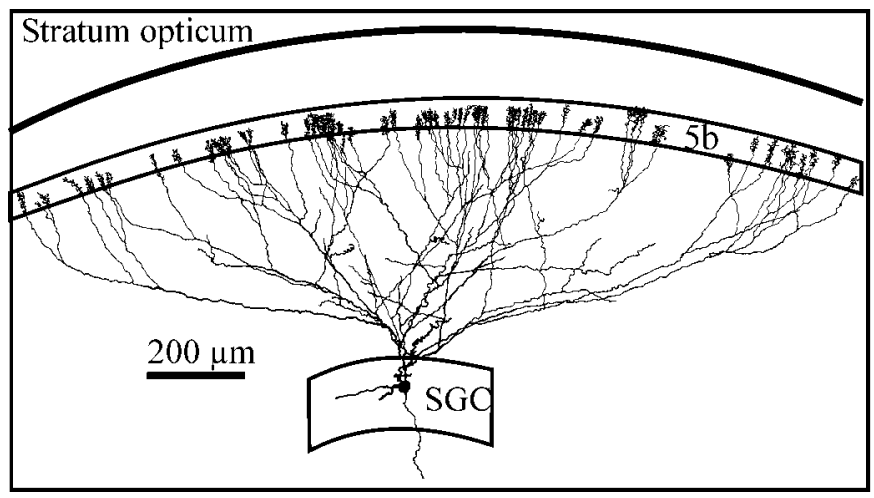

Figure 3. Reconstruction of an SGC-I neuron labeled with biocytin after whole-cell patch recording. The characteristics of this cell type include the large dendritic field, the position of the soma in the upper half of the SGC, and the arrangement of the bottlebrush dendritic endings in the retinorecipient layer $5 \mathrm{~b}$.

\section{Type I neurons}

The SGC-I cell type is characterized by large dendritic fields with basal dendrites that run obliquely through the lower tectal layers, giving rise to secondary and tertiary dendrites that eventually run radially toward the outer layers where specialized distal structures (bottlebrush endings) are positioned in layer 5b (Fig. 3). SGC-I neurons usually have their somata in the outer aspects of the SGC. The cells had stable resting potentials of $-62 \pm 6 \mathrm{mV}$ and input resistances at rest of $67 \pm 30 \mathrm{M} \Omega(n=35)$.

\section{Response to somatic current injection}

We tested the response of the cell to depolarizing weak current pulses (0.2-0.5 nA) injected into the soma. SGC-I neurons responded with an initial burst of two to four action potentials with a fast rising phase, followed by a short afterhyperpolarization (Fig. 4A). With increasing current amplitude, neurons generated additional bursts during depolarization, resulting in highfrequency rhythmic burst firing (Fig. 4B), also known as "chattering." This response mode was found in almost all (27 out of $n=33$ ) of the SGC-I neurons tested. The interburst frequency of the chattering response increased with increasing current amplitude (Fig. $4 C$ ). The intraburst frequency of the first burst also increased with current amplitude, however with different depen-
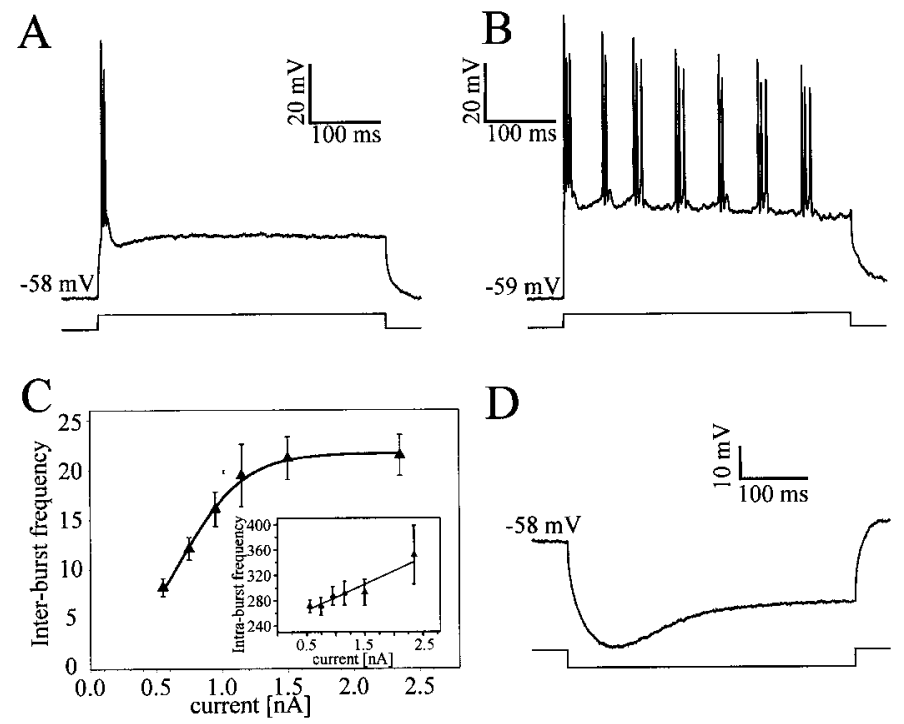

Figure 4. Somatic physiology of SGC-I neurons. $A$, Response to somatic current injection $(0.4 \mathrm{nA})$. After a short burst at the onset containing two to four action potentials, the membrane potential remained constant. $B$, Response of the same neuron to stronger current injection (1.0 nA), showing the typical chattering behavior that contains bursts of action potentials (2-5) with regular interburst intervals. $C$, Chattering frequency plotted against injected current. Inset, Intraburst frequency plotted against injected current. Data shown are means \pm SE. $D$, Depolarizing voltage sag evoked by a hyperpolarizing current pulse $(-0.4 \mathrm{nA})$.

dence on the current amplitude (Fig. 4C, inset). Even with the injection of strong currents of 2-3 nA, cells never changed their response to a tonic firing; rather they continued to chatter.

In all SGC-I neurons tested $(n=22)$, hyperpolarizing current pulses induced a "sag" of the membrane potential (Fig. 4D), characteristic for the presence of a slowly activating H-current.

\section{Response to stimulation of dendritic endings}

In the avian tectum, the retinal ganglion cell axons run along the outer layer of the tectum and enter the tectal layers 1-7 mostly radially in a retinotopic organization (Hunt and Brecha, 1984). The SGC-I neurons have somata in layer 13 and extend their dendrites radially and terminate with bottlebrush dendritic endings in layer 5, where they make synaptic contact with retinal ganglion cell axons (Luksch et al., 1998). In principle, this anatomical organization of the avian tectum allows a stimulation of small groups of retinal ganglion cell axons in layer 3 without direct electrical stimulation of the postsynaptic SGC type I dendrite. To test whether this could be achieved, we placed one stimulus electrode in layer 3 for stimulation of retinal afferents and a second electrode in layer 5 for direct stimulation of dendritic endings (Fig. 1B,C) and compared the response of the SGC-I neuron with both stimuli (Fig. 5).

In all SGC-I cells tested, electrical stimulation of retinal afferents in layers 2-4 resulted in a characteristic sharp-onset cellular response consisting of one to three action potentials riding on a broader depolarization (Fig. 5A). This burst response was often followed by a slight afterhyperpolarization. The onset of the response had an average latency of $11 \pm 2 \mathrm{msec}(n=21)$. The response was abolished in the presence of $10 \mu \mathrm{M} \mathrm{CNQX} \mathrm{(Fig.} 5 A$, inset) for all cells tested $(n=7)$. This CNQX sensitivity is consistent with previous studies (Dye and Karten, 1996) indicating that glutamate is the transmitter at the synapses from retinal afferents onto the bottlebrush endings. The CNQX sensitivity 
A

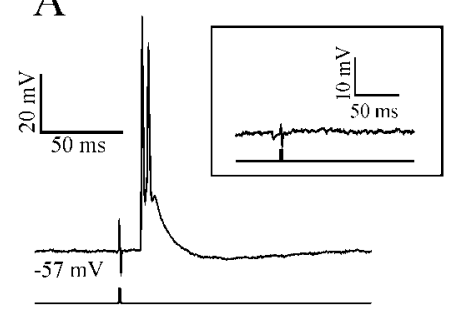

B

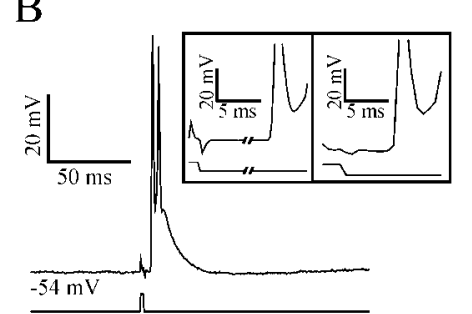

C

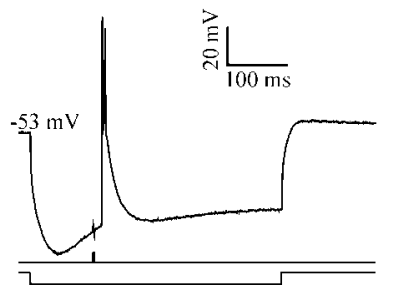

Figure 5. Response of SGC-I neurons to electrical stimulation of retinal afferents. $A$, Synaptic stimulation via electrical stimulation $(1 \mathrm{msec} ; 400 \mu \mathrm{A})$ of retinal afferents with electrodes in layer $2-4$ is shown. Inset, This response is completely abolished after incubation with $10 \mu \mathrm{M}$ CNQX. $B$, Direct electrical stimulation $(2 \mathrm{msec} ; 100 \mu \mathrm{A})$ of bottlebrush dendritic endings with electrodes in layer $5 \mathrm{~b}$ is shown. Note the sharp

onset of the cellular response evoked by either stimulation or the difference in latency. Inset, The same traces in $B$ are shown with a higher time resolution. $C$, Comparable sharp-onset EPSP/burst responses to synaptic stimulation $(1 \mathrm{msec} ; 100 \mu \mathrm{A})$ were elicited when the soma was hyperpolarized by current injection $(-0.6 \mathrm{nA})$.

confirms that the response is caused by synaptic transmission and not by direct electric stimulation of dendritic endings.

Direct electrical stimulation of dendritic endings with a bipolar electrode in layer $5 \mathrm{~b}$ led to a cellular response essentially identical to the response to synaptic stimulation. Here, too, the response had a very sharp onset, consisted of one to three action potentials riding on a slower depolarization, and was often followed by an afterhyperpolarization (Fig. 5B). However, the latency of this response was much shorter $(3.4 \pm 1.5 \mathrm{msec} ; n=21)$. The response was not altered in $50 \mu \mathrm{M}$ CNQX saline (data not shown) but was abolished when the electrode was vertically lifted from the surface of the slice while still in the saline (data not shown). This observation indicates that the response was caused by direct local stimulation of dendritic endings in layer 5 and not by synaptic stimulation or by direct electrical stimulation of the soma.

The sharp-onset response to direct and synaptic stimulation of remote dendritic endings suggests that the dendrites contain voltage-gated conductances that make them excitable. In an attempt to separate the role of the dendritic endings and the soma in the response to synaptic stimulation, we hyperpolarized the soma with somatic current injection. The extent of the dendritic field (Figs. 1B, 3) suggests that dendritic endings at a distance of typically $1000 \mu \mathrm{m}$ from the soma are electrically remote from the soma and therefore are expected to be affected less or not at all by the somatic hyperpolarization. In all neurons tested $(n=5)$, the synaptic stimulation caused a sharp-onset EPSP/burst response at all levels of somatic hyperpolarization, down to -140 $\mathrm{mV}$ (Fig. $5 C$ ). The broader EPSP response increased in amplitude with hyperpolarization and caused the generation of two spikes at a somatic membrane potential of approximately -60 $\mathrm{mV}$. This observation suggests that dendritic voltage-gated channels amplify electrical signals from dendritic endings on their way to the soma.

\section{Type II neurons}

SGC-II neurons have large dendritic fields with a layout of primary, secondary, and tertiary dendrites comparable with that of the SGC-I neurons. The major distinction lies in the position of the bottlebrush endings. The dendritic endings of SGC-II neurons never reach retinorecipient layers 1-7 but remain below layer 8 and often, but not always, show a laminar arrangement (Fig. 6). The somata of SGC-II neurons usually lie in the deeper aspects of the SGC. Neurons of this cell type had stable resting potentials of $-60 \pm 6 \mathrm{mV}$ and input resistances at rest of $134 \pm$ $57 \mathrm{M} \Omega(n=15)$.

\section{Response to somatic current injection}

SGC-II neurons responded to weak depolarizing current pulses with individual action potentials and never showed bursting responses (Fig. 7A). When the amplitude of the current injection

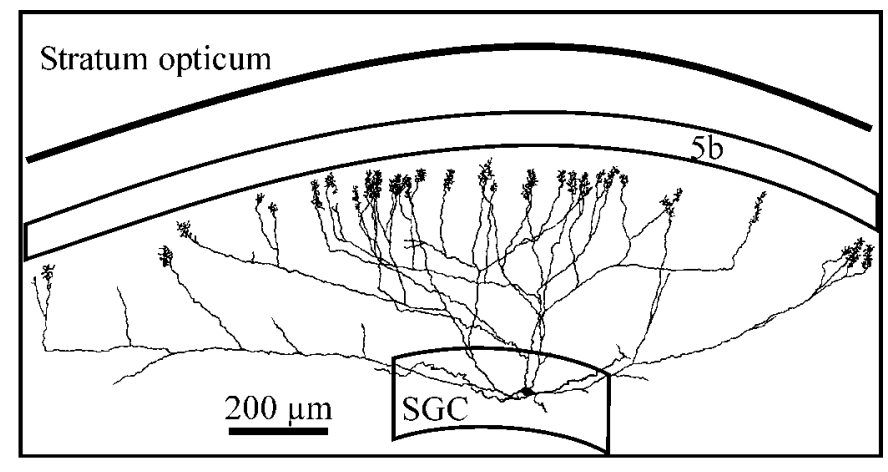

Figure 6. Reconstruction of an SGC-II neuron labeled with biocytin after whole-cell patch recording. This cell type is characterized by large dendritic fields, the position of the soma in the lower half of the SGC, and the position of bottlebrush dendritic endings below the retinorecipient layers.

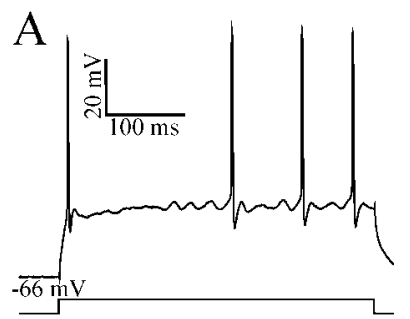

$\mathrm{C}$

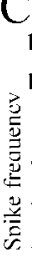
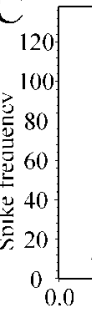
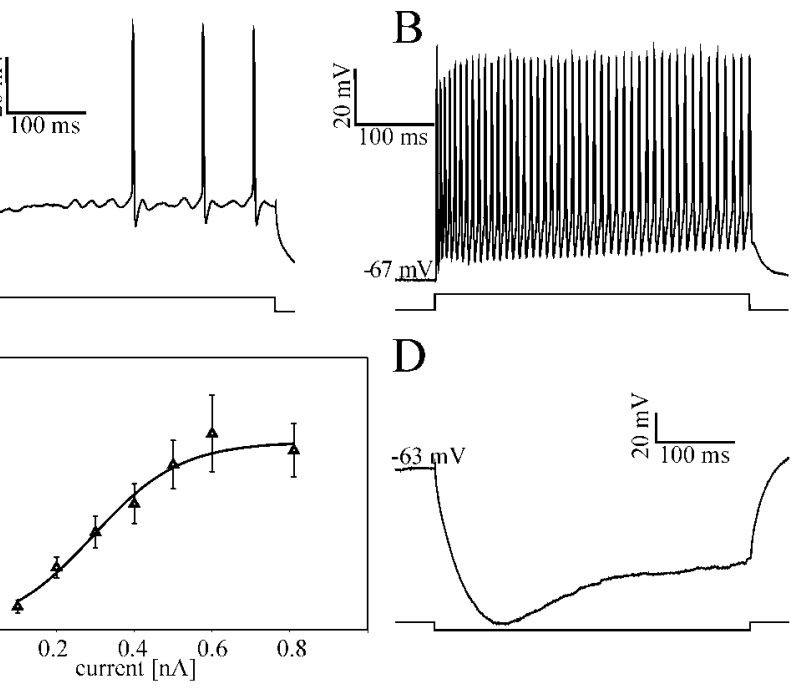

$\mathrm{D}$

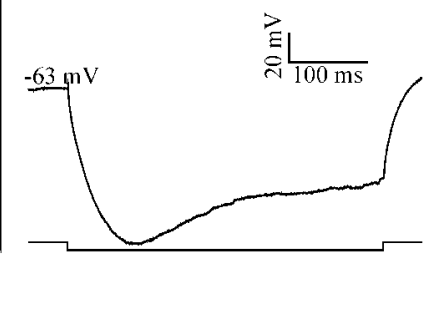

Figure 7. Somatic physiology of SGC-II neurons. $A$, Response to somatic current injection $(0.1 \mathrm{nA})$ consisting of single action potentials. $B$, Tonic response of the same neuron to stronger current injection $(0.7 \mathrm{nA}) . C$, Spike frequency of the tonic response plotted against injected current. Data shown are means \pm SE. $D$, Depolarizing voltage sag evoked by a hyperpolarizing current pulse $(-0.5 \mathrm{nA})$.

was increased, neurons responded with a regular sequence of spikes (Fig. $7 B$ ). The firing frequency increased with increasing current amplitude (Fig. $7 C$ ). None of the SGC-II neurons tested $(n=15)$ showed bursting behavior at any level of depolarization.

Almost all (11/12) type II neurons tested with hyperpolarizing currents showed a voltage sag characteristic for the presence of an H-current (Fig. 7D). 
Figure 8. Response of SGC-II neurons to electrical stimulation of retinal afferents. $A$, Cells responded to synaptic stimulation ( $1 \mathrm{msec} ; 30 \mu \mathrm{A})$ with one to three action potentials riding on a broad EPSP. Inset, This response is completely abolished after incubation with $10 \mu \mathrm{M}$ CNQX. $B$, In some cases, the response to synaptic stimulation ( $1 \mathrm{msec} ; 60 \mu \mathrm{A})$ lasted several hundred milliseconds. $C$, When the soma was hyperpolarized by current injection $(-0.4 \mathrm{nA})$ during the delivery of the synaptic stimulus, cells typically responded to synaptic stimulation $(1 \mathrm{msec} ; 60 \mu \mathrm{A})$ with an EPSP without spikes.

\section{Response to stimulation of retinal afferents}

Electrical stimulation of the retinal afferents (layers 2-4) led to a slow and long-lasting EPSP after a latency of $14 \pm 6$ msec that produced one or several action potentials (Fig. $8 A$ ). The EPSP had variable duration from a minimum of $80 \mathrm{msec}$ to a maximum of $700 \mathrm{msec}$ with an average of $293 \pm 207 \mathrm{msec}$ (Fig. 8B), indicating the activation of a polysynaptic network. The response was blocked with $10 \mu \mathrm{M} \mathrm{CNQX} \mathrm{(Fig.} \mathrm{8A,} \mathrm{inset)} \mathrm{for} \mathrm{all} \mathrm{cells} \mathrm{tested}$ $(n=5)$, indicating the involvement of glutamatergic synaptic transmission. In a few cases in which the stimulation electrodes had been positioned below layer 8, direct stimulation of SGC-II neurons could be achieved. In these cases, the response consisted mostly of single action potentials with a sharp onset after a latency of $4 \pm 1 \mathrm{msec}(n=4)$. In four neurons, we tested the response to synaptic stimulation during somatic hyperpolarization. In all cases this elicited a long-lasting EPSP (Fig. 8C) that, in one case, led to an action potential.

\section{DISCUSSION}

The major results of the present experiments are the following. (1) SGC-I neurons respond with rhythmic bursts (chattering) to depolarizing current injection, whereas SGC-II neurons respond with regular spiking; (2) SGC-I neurons respond with a sharponset EPSP/burst to synaptic stimulation, whereas SGC-II neurons respond with a slow and long-lasting EPSP; and (3) the sharp-onset EPSP/burst response to synaptic stimulation in type I neurons persists when the soma is hyperpolarized.

\section{Type I and II wide-field neurons in birds and mammals}

Among birds, the morphological SGC cell types I and II are not unique to the chicken tectum. Rather, comparable types are found in pigeon tectum (Hunt and Künzle, 1976; Hardy et al., 1987; Karten et al., 1997; Hellmann and Güntürkün, 2001) as well as in other avian species (barn owl, goose, duck, and parrot) $(\mathrm{H}$. Luksch, unpublished observations).

Neurons with the characteristics of avian SGC cells also exist in the superior colliculus of mammals. These "wide-field vertical cells" (Langer and Lund, 1974) are situated in the SGS (Kanaseki and Sprague, 1974). They have large dendritic fields and specialized dendritic endings in upper layers, receive retinal input, and project out of the colliculus toward the thalamic homolog of the avian nucleus rotundus (Ogawa et al., 1985; Mooney et al., 1988; Lee and Hall, 1995; Isa et al., 1998; Major et al., 2000). On anatomical grounds, avian SGC neurons and mammalian SGS neurons appear to be homologous (Major et al., 2000).

\section{Bursts in response to synaptic stimulation}

SGC-I neurons respond with a sharp-onset EPSP/burst to synaptic stimulation. This response persists when the soma is hyperpolarized (Fig. 5). The thin and long dendrites and the sharponset responses in the soma suggest that electrical signals from dendritic endings are amplified on the way to the soma and, possibly, that spikes are generated in the dendrites.

Similar sharp-onset responses have been observed in vitro in wide-field neurons of the rat superior colliculus (Isa et al., 1998) in response to optic tract stimulation. The synaptic coupling had a broad range of latencies up to $17 \mathrm{msec}$, which is comparable with our finding of long average latencies $(11 \mathrm{msec})$ for the monosynaptic connection to type I neurons. Moreover, when the soma of the same wide-field neurons was hyperpolarized by current injection, the cells showed spike generation independent of the somatic membrane potential, a finding that mirrors our results from the type I neurons. Isa et al. (1998) speculated that this result was caused by either dendritic spikes or retinal afferents on the axon of the wide-field neuron. In birds, the second hypothesis can be eliminated because avian retinal afferents do not reach the efferent axons.

Most interestingly, high-frequency bursts have been observed in vivo in response to a small moving spot of light in deep tectal neurons of pigeons (Troje and Frost, 1998) and in the superior colliculus in cat and monkey (Humphrey, 1968; Pauluis et al., 2001). These studies reported two additional features; the burst frequency linearly increased with stimulus speed (Troje and Frost, 1998), and the receptive field displayed a fine structure of spots, i.e., a reproducible discontinuous response to a continuously moving spot of light (Humphrey, 1968).

From these reports, together with our observation of sharponset EPSP/burst responses to synaptic stimulation, the following mechanism for responses to a moving spot of light is hypothesized: each dendritic ending receives inputs from a small receptive field. A moving spot of light successively activates dendritic endings. After activation, a dendritic ending generates a burst. The long dendrites transmit the burst from the dendritic ending to the soma. As a result, the soma responds with a sequence of bursts to a moving spot of light.

\section{Parallel retinotectorotundal motion pathways}

The avian retinotectorotundal pathway possesses multiple information streams and significant dedication to motion processing. Subdivisions of rotundus possess differential preferences for translational motion, motion-in-depth, luminance, and color (Revzin, 1981; Wang and Frost, 1992; Wang et al., 1993). These subdivisions correspond, in part, to the projection fields of the SGC-I and -II cells (Benowitz and Karten, 1976; Karten et al., 1997; Luksch et al., 1998; Hellmann and Güntürkün, 2001).

The difference in response to synaptic stimulation between SGC-I and -II cells may thus have functional significance for the processing of visual information in the two separate retinotectorotundal pathways. In particular, the sharp-onset burst response of motion-sensitive type I neurons seems ideally suited to process time-sensitive visual information present in moving stimuli. Fur- 
thermore, bursts are thought to be a more reliable mode of encoding sensory information (Gabbiani et al., 1996). Moreover, the response in bursts ensures transmission of the signal across unreliable synapses with high fidelity (Lisman, 1997). In contrast, the slow and long-lasting response of SGC-II neurons to synaptic stimulation suggests that these neurons are involved in the processing of visual information that is less sensitive to temporal accuracy.

Of practical consequences, the bursting responses of SGC-I neurons provide an important method of physiological identification in extracellular recordings. Studies on visual response properties are typically performed in vivo with extracellular electrodes that do not allow the identification of the cell type from which recordings are made. On the basis of our findings, data from deep tectal neurons that respond with bursting responses to moving stimuli can be attributed to SGC-I neurons.

\section{Glutamate receptors mediate monosynaptic retinal inputs}

In birds and mammals, retinal input to the visual midbrain is primarily mediated by glutamate that acts on ionotropic and metabotropic receptors, and blocking of these interrupts retinotectal transmission (Canzek et al., 1981; Binns and Salt, 1994; Dye and Karten, 1996; Cirone and Salt, 2000). Because in our experiments the glutamate receptor blocker CNQX completely abolished cellular responses of SGC neurons, we conclude that synaptic transmission at the bottlebrush endings of SGC-I neurons is mediated by glutamate receptors. This conclusion is corroborated by direct electron microscopic observations of retinotectal synapses in the chick (Tömböl and Németh, 1999). For SGC-II neurons, the interpretation is more difficult because several synapses are involved that might be blocked by CNQX incubation.

\section{Retinotopic stimulation in a tectal slice}

Previous studies have investigated cellular responses of avian tectal neurons to electrical stimulation in vivo (Hardy et al., 1984, 1985; Leresche et al., 1986) and in vitro (Dye and Karten, 1996). However, these studies have stimulated the optic nerve or the optic tract, activating a large number of afferent fibers and probably a network of tectal cells.

In birds, retinal ganglion cell axons are organized retinotopically in the outer layers of the avian tectum (Hunt and Brecha, 1984). Retinal axons are spatially separated from postsynaptic SGC-I and -II dendrites except at the dendritic endings where they make synaptic contacts (Luksch et al., 1998). Here, we demonstrate that it is possible to activate wide-field neurons in a tectal slice by stimulation of a few retinal afferents after they have left the stratum opticum. In contrast, in the mammalian superior colliculus, retinotopic electrical stimulation is difficult because retinal afferents enter in the deep stratum opticum and course upward to make synaptic connections through the dendritic fields of the output neurons (Kappers et al., 1967; Kanaseki and Sprague, 1974; Isa et al., 1998).

\section{Chattering neurons in avian tectum, mammalian superior colliculus, and visual cortex}

Our studies revealed that tectal SGC-I neurons respond with a rhythmic burst of spikes (chattering) to sustained depolarization (Fig. 4B), thereby demonstrating that the bursts are generated by mechanisms intrinsic to the cell. The number of action potentials per burst remains constant, whereas the frequency of the bursts is positively correlated with the current strength.
The observed fine structure of bursts (Fig. 4B), notably the afterdepolarization, suggests a mechanism underlying rhythmic bursting that is based on a combination of ion channels (Brumberg et al., 2000) and the coupling between different cell compartments (Pinsky and Rinzel, 1994; Rhodes and Gray, 1994; Mainen and Sejnowski, 1996; Wang, 1999). Whether the suggested mechanism that is based on the coupling between different cell compartments is used in the SGC type I neuron remains to be elucidated.

Rhythmic bursting in response to current injection has been reported previously in unidentified pigeon tectal neurons (Hardy et al., 1987). There, however, the number of action potentials per burst increased with the current strength, whereas the interburst interval was not altered. Studies of the rat SC have revealed wide-field neurons in the superficial layers that generate rhythmic bursting, the frequency of which is correlated with the current strength (Lo et al., 1998; Saito and Isa, 1999). Chattering is also found in superficial pyramidal neurons in the visual cortex of cat in response to depolarizing current injection or to a drifting light bar (Gray and McCormick, 1996) and may be involved in the generation of synchronous oscillations.

In contrast, SGC-II neurons responded to depolarizing current injections with a regular spiking pattern, the frequency of which increased with the current strength. We did not observe bursting behavior or afterhyperpolarizations in these neurons. Cells with comparable physiological characteristics have been reported in the pigeon tectum (Hardy et al., 1987) and the rat SC (Lo et al., 1998; Saito and Isa, 1999) but were not attributed to neurons with a specific morphology.

\section{REFERENCES}

Angaut P, Reperant J (1976) Fine structure of the optic fibre termination layers in the pigeon optic tectum: a Golgi and electron microscope study. Neuroscience 1:93-105.

Benowitz LI, Karten HJ (1976) Organization of the tectofugal visual pathway in the pigeon: a retrograde transport study. J Comp Neurol 167:503-520.

Binns KE, Salt TE (1994) Excitatory amino acid receptors participate in synaptic transmission of visual responses in the superficial layers of the cat superior colliculus. Eur J Neurosci 6:161-169.

Bravo H, Pettigrew JD (1981) The distribution of neurons projecting from the retina and visual cortex to the thalamus and tectum opticum of the barn owl, Tyto alba, and the burrowing owl, Speotyto cunicularia. J Comp Neurol 199:419-441.

Brumberg JC, Nowak LG, McCormick DA (2000) Ionic mechanisms underlying repetitive high-frequency burst firing in supragranular cortical neurons. J Neurosci 20:4829-4843.

Canzek V, Wolfensberger M, Amsler U, Cuenod M (1981) In vivo release of glutamate and aspartate following optic nerve stimulation. Nature 293:572-574.

Chaves LM, Hodos W (1998) Color reversal-learning deficits after tectofugal pathway lesions in the pigeon telencephalon. Behav Brain Res 90:1-12.

Cirone J, Salt TE (2000) Physiological role of group III metabotropic glutamate receptors in visually responsive neurons of the rat superficial superior colliculus. Eur J Neurosci 12:847-855.

Dye JC, Karten HJ (1996) An in-vitro study of retinotectal transmission in the chick: role of glutamate and GABA in evoked field potentials. Vis Neurosci 13:747-758.

Frost BJ (1978) Moving background patterns alter directionally specific responses of pigeon tectal neurons. Brain Res 151:599-603.

Frost BJ, DiFranco DE (1976) Motion characteristics of single units in the pigeon optic tectum. Vision Res 16:1229-1234.

Frost BJ, Nakayama K (1983) Single visual neurons code opposing motion independent of direction. Science 220:744-745.

Gabbiani F, Metzner W, Wessel R, Koch C (1996) From stimulus encoding to feature extraction in weakly electric fish. Nature 384:564-567.

Gray CM, McCormick DA (1996) Chattering cells: superficial pyramidal neurons contributing to the generation of synchronous oscillations in the visual cortex. Science 274:109-113.

Hardy O, Leresche N, Jassik-Gerschenfeld D (1984) Postsynaptic potentials in neurons of the pigeon's optic tectum in response to afferent 
stimulation from the retina and other visual structures: an intracellular study. Brain Res 311:65-74.

Hardy O, Leresche N, Jassik-Gerschenfeld D (1985) Morphology and laminar distribution of electrophysiologically identified cells in the pigeon's optic tectum: an intracellular study. J Comp Neurol 233:390-404.

Hardy O, Audinat E, Jassik-Gerschenfeld D (1987) Electrophysiological properties of neurons recorded intracellularly in slices of the pigeon optic tectum. Neuroscience 23:305-318.

Hellmann B, Güntürkün O (2001) Structural organization of parallel information processing within the tectofugal visual system of the pigeon. J Comp Neurol 429:94-112.

Hodos W, Karten HJ (1974) Visual intensity and pattern discrimination deficits after lesions of the optic lobe in pigeons. Brain Behav Evol 9:165-194.

Hughes CP, Pearlman AL (1974) Single unit receptive fields and the cellular layers of the pigeon optic tectum. Brain Res 80:365-377.

Humphrey NK (1968) Responses to visual stimuli of units in the superior colliculus of rats and monkeys. Exp Neurol 20:312-340.

Hunt SP, Brecha N (1984) The avian optic tectum: a synthesis of morphology and biochemistry. In: Comparative neurology of the optic tectum (Vanegas H, ed), pp 619-648. New York: Plenum.

Hunt SP, Künzle H (1976) Observations on the projections and intrinsic organization of the pigeon optic tectum: an autoradiographic study based on anterograde and retrograde, axonal and dendritic flow. J Comp Neurol 170:153-172.

Hunt SP, Webster KE (1975) The projection of the retina upon the optic tectum of the pigeon. J Comp Neurol 162:433-445.

Isa T, Endo T, Saito Y (1998) The visuo-motor pathway in the local circuit of the rat superior colliculus. J Neurosci 18:8496-8504.

Jassik-Gerschenfeld D, Guichard J (1972) Visual receptive fields of single cells in the pigeon's optic tectum. Brain Res 40:303-317.

Jassik-Gerschenfeld D, Minois F, Conde-Courtine F (1970) Receptive field properties of directionally selective units in the pigeon's optic tectum. Brain Res 24:407-421.

Kanaseki T, Sprague JM (1974) Anatomical organization of pretectal nuclei and tectal laminae in the cat. J Comp Neurol 158:319-337.

Kappers CUA, Huber GC, Crosby EC (1967) The comparative anatomy of the nervous system of vertebrates including man. New York: Hafner.

Karten HJ, Revzin AM (1966) The afferent connections of the nucleus rotundus in the pigeon. Brain Res 2:368-377.

Karten HJ, Cox K, Mpodozis J (1997) Two distinct populations of tectal neurons have unique connections within the retinotectorotundal pathway of the pigeon (Columba livia). J Comp Neurol 387:449-465.

Langer TP, Lund RD (1974) The upper layers of the superior colliculus of the rat: a Golgi study. J Comp Neurol 158:418-435.

Laverghetta AV, Shimizu T (1999) Visual discrimination in the pigeon (Columba livia): effects of selective lesions of the nucleus rotundus. NeuroReport 10:981-985.

Lee P, Hall WC (1995) Interlaminar connections of the superior colliculus in the tree shrew. II: Projections from the superficial gray to the optic layer. Vis Neurosci 12:573-588.

Leresche N, Hardy O, Audinat E, Jassik-Gerschenfeld D (1986) Synaptic transmission of excitation from the retina to cells in the pigeon's optic tectum. Brain Res 365:138-144.
Lisman JE (1997) Bursts as a unit of neural information: making unreliable synapses reliable. Trends Neurosci 20:38-43.

Lo FS, Cork RJ, Mize RR (1998) Physiological properties of neurons in the optic layer of the rat's superior colliculus. J Neurophysiol 80:331-343.

Luksch H, Cox K, Karten HJ (1998) Bottlebrush dendritic endings and large dendritic fields: motion-detecting neurons in the tectofugal pathway. J Comp Neurol 396:399-414.

Mainen ZF, Sejnowski TJ (1996) Influence of dendritic structure on firing pattern in model neocortical neurons. Nature 382:363-366.

Major DE, Luksch H, Karten HJ (2000) Bottlebrush dendritic endings and large dendritic fields: motion-detecting neurons in the mammalian tectum. J Comp Neurol 423:243-260.

Mooney RD, Nikoletseas MM, Ruiz SA, Rhoades RW (1988) Receptive-field properties and morphological characteristics of the superior collicular neurons that project to the lateral posterior and dorsal lateral geniculate nuclei in the hamster. J Neurophysiol 59:1333-1351.

Ogawa T, Takimori T, Takahashi Y (1985) Projection of morphologically identified superior colliculus neurons to the lateral posterior nucleus in the cat. Vision Res 25:329-337.

Pauluis Q, Baker SN, Olivier E (2001) Precise burst synchrony in the superior colliculus of the awake cat during moving stimulus presentation. J Neurosci 21:615-627.

Pinsky PF, Rinzel J (1994) Intrinsic and network rhythmogenesis in a reduced Traub model for CA3 neurons. J Comput Neurosci 1:39-60.

Ramón y Cajal S (1911) Le lobe optique des vertébrés inférieurs, toit optique des oiseaux. In: Histologie du système nerveux de l'homme et des vertébrés (Ramón y Cajal S, ed), pp 196-212. Madrid.

Remy M, Güntürkün O (1991) Retinal afferents to the tectum opticum and the nucleus opticus principalis thalami in the pigeon. J Comp Neurol 305:57-70.

Revzin AM (1981) Functional localization in the nucleus rotundus. In: Neural mechanisms of behavior in the pigeon (Granda AM, Maxwell JH, eds), pp 165-175. New York: Plenum.

Rhodes PA, Gray CM (1994) Simulations of intrinsically bursting neocortical pyramidal neurons. Neural Comput 6:1086-1110.

Saito Y, Isa T (1999) Electrophysiological and morphological properties of neurons in the rat superior colliculus. I. Neurons in the intermediate layer. J Neurophysiol 82:754-767.

Tömböl T, Németh A (1999) Direct connections between dendritic terminals of tectal ganglion cells and glutamate-positive terminals of presumed optic fibres in layers $4-5$ of the optic tectum of Gallus domesticus. Neurobiology (Bp) 7:45-67.

Troje N, Frost B (1998) The physiological fine structure of motion sensitive neurons in the pigeon's optic tectum. Soc Neurosci Abstr 24:642.9.

Wang XJ (1999) Fast burst firing and short-term synaptic plasticity: a model of neocortical chattering neurons. Neuroscience 89:347-362.

Wang Y, Frost BJ (1992) Time to collision is signalled by neurons in the nucleus rotundus of pigeons. Nature 356:236-238.

Wang Y, Jiang S, Frost BJ (1993) Visual processing in pigeon nucleus rotundus: luminance, color, motion, and looming subdivisions. Vis Neurosci 10:21-30. 